\title{
0723 A STUDY OF WARFARE INJURIES DRAINING TO TEACHING HOSPITAL, ANURADHAPURA, SRI LANKA
}

\author{
10.1136/ip.2010.029215.723
}

H K Wijayarathne*, G G G T Amarakoon, H B D Jeewantha, J K Senanayake, S D Dharmaratne Correspondence: Department of Anatomy, Faculty of Medicine and Allied Health Sciences, Rajarata University of Sri Lanka, Saliyapura, Anuradhapura, Sri Lanka

Background Armed conflict has been a major cause of ill health and death throughout history and not received the same attention from public health practitioners and researchers as other causes of illness. But has been projected to be the 8th most important cause of death by 2020.The Sri Lankan Civil War was an on-and-off insurgency against the government by the Liberation Tigers of Tamil Eelam, a separatist militant organisation which fought to create an independent Tamil state. After a 30 month long military campaign, the Sri Lankan military defeated the Tamil Tigers in May 2009.

Objectives To determine the incidence of warfare injuries draining to Teaching Hospital, Anuradhapura, Sri Lanka and interventions for those injuries.

Methods This is a retrospective analytical study and obtained data from May 2007 to May 2009. All the patients admitted to surgical units with warfare injuries were collected from bed head tickets.

Results Total admissions to the surgical unit of TH/A is 22 707 and out of which $85.41 \%$ were causalities including 5574 Army Casualties and 13821 civil Casualties. Eighteen percent of army causalities were managed by Laparotomies, $0.25 \%$ by Thoracotomies and $66.54 \%$ by other surgical procedures. Fifteen percent of total army causalities were end up with amputations

Conclusions Higher percentage of total hospital admissions on surgical units was due to causalities out of which considerable percentage due to warfare injuries. At the battle, thoracic region of a soldier is covered with an armour, but may have not been adequate abdominal cover. So the Injuries to the abdominal organs was much higher than thoracic organs. To prevent those abdominal injuries, bullet proof abdominal armours can be introduced. Number of amputations shows the incidence of disable individuals and rehabilitation programs should launch for them. 